\title{
Primary, Secondary, and Special Education School Teachers
}

National Cancer Institute

\section{Source}

National Cancer Institute. Primary, Secondary, and Special Education School Teachers. NCl Thesaurus. Code C122500.

The teaching professions that include elementary school teachers, middle school teachers, middle school career/technical education teachers, secondary school teachers, secondary school career/technical education teachers, middle school special education teachers, and secondary school special education teachers. 